\title{
MATRIMONIO Y FAMILIA EN EL ORDENAMIENTO JURÍDICO EUROPEO*
}

\author{
POR \\ JÖRG GEERLINGS \\ Profesor de Derecho Público \\ Universidad de Colonia
}

\section{PREMISA INTRODUCTORIA}

«El matrimonio y la familia encuentran especial protección en el ordenamiento del Estado». Así se pronuncia el art. 6. 1 GG de la RFA. Pero a la vista de la más reciente jurisprudencia del Tribunal Constitucional Federal alemán sobre el registro de parejas de hecho, sin duda podemos plantearnos a continuación la decepcionante pregunta: «¿realmente se encuentran todavía protegidos?». Debemos, sin embargo, levantar la mirada más allá del propio ámbito alemán. Y sobre todo cuando hasta ahora la jurisprudencia alemana no ha tenido en cuenta apenas la del TEDH ${ }^{1}$,

* Traducción del alemán al español por Carlos Vidal Prado, Profesor Titular de Derecho Constitucional de la UNED. La primera versión de este texto se presentó por el autor en el Seminario Hispano-Alemán de Derecho Público, celebrado en la Facultad de Derecho de la UNED en febrero de 2006, en el marco de la Acción Integrada HA2003-110 «Fundamentos y principios comunes de la protección de derechos fundamentales en Europa».

1 Son sintomáticos los casos de dos sentencias del TEDH: el caso "Görgülü/Alemania", NJW 2004, p. 3397; y el caso "Carolina/Alemania", NJW 2004, 2647. Sobre esto puede verse Tettinger, P.J., "Steine aus dem Glashaus», JZ 2004, p. 1144. 
que, al contrario que en Austria, no tiene ningún rango constitucio$\mathrm{nal}^{2}$.

El BVerfG había manifestado ya en 1987, con toda razón, sobre la presunción de inocencia contenida en el art. 6.2 del CEDH:

«Para la interpretación de la Ley Fundamental deben tenerse también en consideración los contenidos y sucesivos desarrollos del CEDH (...) Asimismo las leyes (...) deben interpretarse y aplicarse en conexión con las obligaciones de Derecho internacional a las que está vinculada la RFA, también cuando dichas leyes se han aprobado con posterioridad al Tratado internacional vigente; por lo tanto no puede sostenerse que el legislador, en el caso de que no esté suficientemente fundada su actuación, pueda apartarse de esas obligaciones jurídico-internacionales de la RFA o que pueda posibilitar la violación de dichas obligaciones» ${ }^{3}$.

Se ha de estar de acuerdo con este reconocimiento. Distinto de ello es la apelación por la parte interesada a desarrollos «más progresistas" en el extranjero, especialmente cuando el Derecho nacional no conduce a los resultados deseados. Entre tanto se apela a que el Derecho europeo debe desarrollarse conforme a la "Filosofía de una época", con relación a los aspectos aquí contemplados, con especial atención a la jurisprudencia del TEDH y del TJCE, que deberían haberse acercado a ella todavía más.

Matrimonio y familia, que se presentan como dos bienes jurídicos independientes, pero que se relacionan inseparablemente el uno con el otro, son de modo natural dos presupuestos esenciales para la pervivencia de la humanidad y de sus naciones. La relación de una sociedad con esas instituciones nos dice mucho sobre cómo puede desarrollarse esa sociedad y sobre cómo lo hará. Se trata, por supuesto, de la ya citada "Filosofía de una época», que pone en cuestión lo relativo a esos institutos y su vigencia, y con ello debilita las capacidades futuras de nuestra sociedad europea ${ }^{4}$. Un ejemplo claro lo tenemos en las

2 Cfr., con relación a la influencia de la protección de los Derechos Fundamentales en Europa sobre la jurisprudencia alemana, FROWEIN, J. A., "Der europäische Grundrechtsschutz und die deutsche Rechtsprechung", NVwZ 2002, p. 29; además, sobre la llamada "Bermuda-Dreick» entre Luxemburgo, Estrasburgo y Karlsruhe, vid. TetTINGER, P. J., "Die Charta der Grundrechte der Europäischen Union», NJW 2001, pp. 1010 y 1012.

3 Cfr. BVerfGE 74, 258 (370); vid. además BVerfG(K), EuGRZ 2004, pp. 317, 318 y ss.) con un profundo análisis de la jurisprudencia del TEDH sobre el art. 8 del CEDH.

4 Vid. LEWIS, J., "The End of Marriage?, Individualism and Intimate Relations", 2002. 
actuales discusiones políticas sobre el llamado matrimonio homosexual $^{5}$.

Esto afecta también de modo evidente a España; puesto que el nuevo Gobierno del Presidente Zapatero ha introducido, contra la fuerte oposición de importantes grupos de la sociedad, entre ellos las Iglesias, el matrimonio homosexual, así como el derecho a la adopción de las parejas homosexuales.

\section{EL FACTOR DEMOGRÁFICO}

En toda Europa, sobre todo en países como Alemania, Italia y España, se registran en la actualidad dramáticos cambios demográficos. El número de nacimientos se reduce de manera drástica; y junto a ello se reduce el tiempo de vida laboral de los que todavía tienen capacidad de trabajar y además se eleva la esperanza de vida de las personas mayores que reciben una pensión de jubilación. Las consecuencias de una así llamada "double aging" para la sociedad civil del futuro, para el sistema educativo y formativo y la capacidad de innovación, para el mercado de trabajo, el mercado de bienes y financiero, para los seguros de jubilación y para todo lo que tiene que ver con el Estado social, pero en parte también para la política de inmigración, no se han determinado todavía de modo completo, ni mucho menos se han ponderado en toda su gravedad ${ }^{6}$. Junto a ello tenemos que el número de matrimonios continúa descendiendo, y el de divorcios aumenta. Parece que las personas tienden a convertir la autorrealización individual en el lema dominante de su estilo de vida. En este ámbito juega un papel importante no sólo la política, sino también el orden jurídico (constitucional), pues con él se contribuye a asegurar la identificación a nivel nacional y europeo de unos valores que impregnan sus líneas de actuación.

En definitiva, todos estos son elementos de un amplio escenario que todavía está por iluminar, del que se derivarán seguras consecuencias, y habrá que valorar si puede detenerse, y cómo, esta tendencia.

${ }^{5}$ Cfr. Frankfurter Allgemeine Zeitung, 17.5.2004, p. 1. En esta línea, recientemenmte, DETHLOFF, N., "Adoption durch gleichgeschlechtliche Paare», ZRP 2004, pp. 195 y ss.; en este momento resulta especialmente "progresista" España, que acaba de reconocer junto con el matrimonio de parejas homosexuales el derecho a la adopción de estas parejas.

${ }^{6}$ Cfr. Tettinger, P. J., en: Stern/Tettinger (Coords.), Kölner Gemeinschaftskommentar zur Europäischen Grundrechte-Charta, 2005, Art. 9, Parte II, 6. 
No sorprende, por tanto, que precisamente ahora en Alemania, donde según las estadísticas nacen solamente 1,3 niños por pareja, la cuestión de la "familia", con razón, figure como centro de atención. La nueva "Gran Coalición" intenta de modo continuo, desde hace semanas, poner en marcha nuevas propuestas e ideas, para intentar hacer más agradable el deseo de nuevos niños, hacerlo más atractivo desde el punto de vista económico, o al menos más llevadero. En especial se trata de propuestas que tratan de mejorar las circunstancias que permitan hacer conciliables el trabajo y la familia.

Acertadamente se ha planteado también la cuestión, en este sentido, de si estos nuevos empeños políticos relativos al ámbito de la familia no tienen, al fin y al cabo, en su punto de mira a personas concretas y reales, que tienen más de 18 años; en una palabra: ¡los electores! La cuestión de la familia, sin embargo, desde mi punto de vista, no debe plantearse sólo en función de los intereses electorales o de puras razones económicas.

\section{LA PROTECCIÓN DE MATRIMONIO Y FAMILIA EN EL DERECHO EUROPEO}

\section{Derecho internacional y regulación a nivel europeo}

a) El matrimonio, la familia y el derecho a la educación son objeto de preocupación internacional así como de las Declaraciones de protección de Derechos Humanos ${ }^{7}$. Ya la Declaración Universal de Derechos Humanos de las Naciones Unidas de 10.12.1948 (DUDH), se ocupaba del matrimonio y la familia ${ }^{8}$. En ella se dice, en el artículo 16.1.1: "Los hombres y las mujeres, a partir de la edad núbil, tienen derecho, sin restricción alguna por motivos de raza, nacionalidad o religión, a casarse y fundar una familia».

Debemos citar también el Pacto Internacional de Derechos civiles y políticos. Este Pacto es parte sustancial de la Carta Internacional de Derechos Humanos y establece la obligación jurídica de los Estados firmantes a respetar los derechos en él reconocidos, así como a tomar las medidas necesarias para que esos derechos puedan ejercerse de modo

7 Cfr. TetTinger, P. J., "Der grundgesetzlich gewährleistete besondere Schutz von Ehe und Familie“, en: Essener Gespräche, Tomo 35, 2001, pp. 133 y ss.

8 Sobre su indiscutible eficacia jurídica cfr. NowAK, M., CCPR-Kommentar, 1989, Introducción, número marginal 2; SIEGHART, P., Die geltenden Menschenrechte, 1988, pp. 73 y ss. 
real y efectivo (Art. 2) $)^{9}$. El Pacto considera la familia como «núcleo natural de la Sociedad" y le garantiza un "derecho a la protección a través de la sociedad y del Estado" (Art. 23.1). De igual modo que la declaración de las Naciones Unidas, el Pacto reconoce también el derecho de mujer y hombre, cuando tengan la edad que les capacite para casarse, "a contraer matrimonio y a fundar una familia" (Art. 23.2). Los Estados firmantes se comprometen a distintas obligaciones, entre ellas a preocuparse de la «necesaria protección de los niños en caso de disolución del matrimonio" (Art. 23.4, 2). Luego se unen de modo inseparable, en este Pacto internacional, el instituto jurídico del matrimonio con el status de los potenciales hijos.

b) El tradicional instituto jurídico de la pareja monógama como la unión en absoluta igualdad de condiciones del hombre y la mujer pertenece a los valores culturales centrales europeos, como se refleja, por ejemplo, en el artículo 32 de la Constitución Española, y la familia como núcleo sustancial de la sociedad humana, como también se señala en el art. 16 de la Carta Social Europea ${ }^{10}$.

En el plano global europeo debe citarse, en primer lugar, el Convenio europeo de Derechos Humanos y Libertades Fundamentales de 4.11.1950 ${ }^{11}$. Otros reconocimientos para el matrimonio y la familia los encontramos en la Carta Social Europea de 18.10.1961 ${ }^{12}$. Sin embargo, hasta el momento ésta no ha sido ratificada todavía por todos los Estados miembros del Consejo de Europa. La Carta Social Europea caracteriza la familia como "célula fundamental de la sociedad", y le garantiza el "derecho a una adecuada protección social, jurídica y económica, para lograr su pleno desarrollo» (Parte I, Núm. 16).

c) Los Estados miembros de la UE han regulado en todo caso en sus textos constitucionales la protección del matrimonio y la familia, aunque sea en diferente medida y con diversos grados de protección ${ }^{13}$. El matrimonio como institución, tal y como se hace en la Constitución alemana, no se regula en todos los Estados de la Unión Europea, sino

9 La aplicación directa dentro de cada Estado es sin embargo problemática, cfr. HöVELBERNDT, A., "Ehe, Familie und Erziehungsrecht als Thema internationaler Regelungen zum Schutze der Menschenrechte, der Verfassungen der EU-Mitgliedstaaten und der deutschen Bundesländer», FPR 2004, pp. 117 y ss.

10 Cfr. Tettinger, P. J,. (Nota a pie de página núm. 2), pp. 1010 y 1012.

${ }^{11}$ BGBI. 1952 II, p. 685; sobre la influencia en el ordenamiento jurídico alemán, vid. Frowein, J. A., (Nota a pie de página núm. 2), p. 9.

12 BGBI. 1964 II, p. 1262. Cfr. http://www.acnur.org/biblioteca/pdf/1934.pdf

13 Cfr. una visión general en Hövelbernd, A. (Nota a pie de página núm. 9), p. 117 (especialmente 118 y ss.). 
que, en parte, se abordan sólo aspectos aislados como la primacía del divorcio civil ante la boda eclesiástica (como el art. 21.2 Constitución de Bélgica; Art. 21 de la de Luxemburgo) o en los que el matrimonio se reserva exclusivamente a las previsiones que se establezcan en la ley (Capítulo 8, Art. 2.2 de la Constitución sueca). Junto a la Constitución alemana, contienen abundantes regulaciones las constituciones de Grecia. Irlanda, Italia y España.

El art. 41.3.1 de la Constitución irlandesa describe el matrimonio como «institución..., en la que se basa la familia», y obliga al Estado a "preservarla con especial solicitud" y "protegerla contra todo ataque». La Constitución griega favorece también al matrimonio con la «protección del Estado", según el art. 21.1. La Constitución española garantiza al hombre y a la mujer el «derecho a contraer matrimonio con plena igualdad jurídica" (Art. 32.1). El precepto incluido en el art. 29.1 de la Constitución italiana se basa también en una relación de simbiosis entre matrimonio y familia, de modo semejante al art. 41.3.1 de la Constitución irlandesa. Es interesante el punto de vista de la Constitución polaca de $1997^{14}$, como uno de los nuevos Estados miembros de la UE, en la cual el matrimonio, en cuanto que "unión de hombre y mujer», se sitúa junto a la familia, la maternidad y los derechos de los padres «bajo la protección y la custodia de la República de Polonia" (Art. 18 Constitución polaca). La Constitución de Eslovenia encomienda las futuras determinaciones sobre el matrimonio, por el contrario, al legislador (art. 53.2 Constitución eslovena), y no incluye ningún otro tipo de consideraciones.

Por su parte, los contenidos relativos a la familia se detallan de modo más amplio en las Constituciones de los Estados miembros ${ }^{15}$. Es considerada como "fundamento de la conservación y el desarrollo de la nación» (Art. 21 Constitución griega), como "grupo unitario natural, primario y fundamental de la sociedad y como institución moral poseedora de derechos inalienables e imprescriptibles, anteriores y superiores a toda ley positiva" (Art. 41.1), como " elemento fundamental de la sociedad" (Art. 67.1 Constitución de Portugal) o sencillamente como una "sociedad natural basada en el matrimonio" (Art. 29.1 Constitución italiana).

14 Sobre el desarrollo constitucional de Polonia, puede verse en detalle BANASZAK, B., Einführung in das polnische Verfassungsrecht, 2003, pp. 11 y ss.

15 Art. 6.1 GG; Art. 22 Constitución belga; Preámbulo de la Constitución francesa de 1946; Art. 21.1,2 de la Constitución griega; Art. 41 de la Constitución de Irlanda; Art. 29 de la Constitución italiana; Art. 11.2 de la Constitución de Luxemburgo; Art. 26.1, 2 y art. 67 de la Constitución de Portugal; Art. 39.1 CE. 
La mayoría de las veces se regula la obligación positiva de protegerla. Así se encuentra la familia «bajo la especial protección del ordenamiento del Estado" (Art. 6.1 GG) o "bajo la protección del Estado» (Art. 21.1 Constitución griega). Otras Constituciones garantizan la protección de "la familia en su constitución y autoridad" (Art. 41.1.2 Constitución irlandesa) o garantizan a la familia un "derecho a la protección a través de la sociedad y del Estado..." (Art. 67.1 Constitución portuguesa). El art. 11.2 de la Constitución de Luxemburgo garantiza «los derechos naturales (...) de la familia». La Constitución francesa protege la familia en el Preámbulo de la Constitución de 1946, que se asume como parte de la Constitución actual, y establece que la Nación le proporciona "las condiciones necesarias para su desarrollo". Junto a estas disposiciones fundamentales pueden encontrarse, en algunos casos, regulaciones más amplias y detalladas ${ }^{16}$.

\section{Artículos 8 y 12 del CEDH}

Con relación a la vida familiar que, conforme al art. 8.1 del $\mathrm{CEDH}$, debe protegerse junto a la vida privada, es claro, según la jurisprudencia del TEDH de Estrasburgo, que detrás subyace en primera línea la esfera de convivencia común entre padres e hijos: «Para un progenitor y su hijo estar juntos constituye una parte fundamental de la vida familiar» ${ }^{17}$.

También el texto del art. $12 \mathrm{CEDH}$ deja traslucir que de lo que se trata es del derecho a fundar una familia ( $A$ partir de la edad núbil, el hombre y la mujer tienen derecho a casarse y a fundar una familia según las leyes nacionales que rijan el ejercicio de este derecho" $)^{18}$. En este sentido, sin embargo, el concepto de familia, no se limita a la familia en sentido reducido, como se entiende hasta ahora en el constitucionalismo alemán - por cierto, de igual modo que en el art. 23.2 del Pacto de derechos civiles y políticos de la ONU-, sino que abarca hasta tres generaciones, a relaciones como las que se refieren a los padres que tienen sin más que asumir un hijo no matrimonial de su hija.

16 Cfr. Hövelberndt, A., (Nota a pie de página núm. 9), pp. 117 y 119.

17 Así la sentencia del TEDH sobre el caso "Kutzner/Alemania», cfr. EuGRZ 2002, pp. 244 y 248 , número marginal 58, con abundantes citas de jurisprudencia sobre el particular.

18 Cfr. Frowein, J. A / Peukert, W., EMRK-Kommentar, 2. a edición, 1996, Art. 8 número marginal 15; vid. también Tribunal Federal suizo, EuGRZ 2002, 616 (617 y ss.) sobre una prohibición legal de matrimonio entre un padrastro y su hijastra. 
La vida familiar abarca en todo caso a las relaciones entre ese tipo de "parientes cercanos", que pueden jugar un papel esencial en la familia, como las que existen entre abuelos y nietos ${ }^{19}$.

Necesaria para la eficacia positiva del art. $8 \mathrm{CEDH}$ es, en todo caso, la existencia real de una vida familiar, en la que pueda intervenirse por parte estatal ${ }^{20}$. En lo que se refiere a familiares más lejanos, deberían examinarse criterios que excedan los de la consanguinidad, en la medida en que puedan expresarse de modo significativo, a través de la convivencia en un hogar común o de las diversas circunstancias de la vida familiar ${ }^{21}$. EI TEDH ha señalado, en una Decisión relativamente reciente (de 13.2.2003, en la causa Odièvre vs. Francia) y digna de ser resaltada (se trataba del recurso de una mujer cuyo nacimiento se produjo en el anonimato, que solicitaba la información sobre su origen), que no se habría violado el art. $8 \mathrm{CEDH}$, puesto que un simple vínculo biológico, en ausencia de una íntima, real y personal relación no es suficiente para fundamentar la existencia de una vida familiar en el sentido de lo que el precepto garantiza.

La estrecha ligazón que con esta idea se expresa entre matrimonio y familia aparece clara en el Convenio Europeo de Derechos Humanos, cuando en su artículo 12 se califica como un solo derecho el derecho a casarse y a fundar una familia ( «the right to marry ant to found a family»). Ahí la identificación del precepto clave es aún más clara en las versiones inglesa y francesa de ese artículo 12 ("this right», "ce droit») que en la alemana 22 ; en forma muy semejante se expresan también el artículo 41.3.1 de la Constitución irlandesa y el artículo 29.1 de la Constitución italiana.

19 TEDH, caso "Marckx/Bélgica", EuGRZ 1979, 454 (458); Frowein, J. A / PeUKERT, W., (Nota a pie de página 18), Art. 8 número marginal 16.

${ }_{20}$ Cfr., de la jurisprudencia reciente del TEDH, el caso "Taskin/Alemania», EuGRZ 2002, 593, aunque esto no puede afirmarse a priori para las parejas que vivan separadas.

${ }^{21}$ Así, Frowein, J. A / Peukert, W., (Nota a pie de página núm. 18), Art. 8 número marginal 16.

${ }^{22}$ Cfr. Frowein, J. A / Peukert, W., (Nota a pie de página núm. 18), Art. 12 número marginal 6, en donde se hace además hincapié en el hecho de que tanto la Comisión como el Tribunal habían visto ya en el matrimonio el fundamento para fundar una familia. 


\section{La Carta Europea de Derechos Fundamentales}

La Carta de Derechos Fundamentales de la Unión Europea, que como Parte II debe considerarse como un elemento esencial del Tratado por el que se instituye una Constitución para Europa, vuelve en cualquier caso a considerar el matrimonio y la familia (cfr. arts. 7, 9 y 33 de la Carta). A pesar de que no está claro lo que pueda suceder con el proceso de rectificación tras los Referenda negativos en Francia y Holanda, la Carta de Derechos Fundamentales se ha venido aplicando como fuente de conocimiento complementaria en la literatura y en la praxis jurídica.

Las regulaciones de la Carta de Derechos de la UE se basan sobre todo en las tradiciones constitucionales de los Estados miembros, las disposiciones de Derecho comunitario originario, el CEDH y la Carta Social Europea. En el ámbito europeo, en lo que se refiere a las reformas emprendidas actualmente para convertir lo que hasta ahora es una agencia de mercado interno, primariamente orientada hacia el ámbito económico, en una Unión más estrecha en el marco de una unión de los pueblos europeos, es necesario, antes que nada, establecer en el derecho originario, de modo literal y destacado, los valores materiales comunes europeos, a través de unas formulaciones que, en la medida de lo posible, sean lo más fácilmente comprensibles. Debe realizarse pues un esfuerzo para aplicar los correspondientes valores, lo cual se trata de una tarea no sólo para juristas. Esto debe tenerse en cuenta de manera muy especial a la hora de analizar un conglomerado de valores tan sensible como el matrimonio y la familia, instituciones jurídicas tradicionales, que pertenecen a los centrales valores culturales europeos, y con relación a los cuales no deben olvidarse sus raíces cristianas ${ }^{23}$.

Con una intensificación de la discusión sobre los valores cristianos que impregnan Europa se contribuiría, por cierto, a fijar los fundamentos para asegurar unas convicciones en valores atlánticos comunes, que precisamente se han vuelto más importantes para el mundo libre, pues se hallan en el trasfondo de las exigencias planteadas antes por el terrorismo y ahora con otros más recientes desacuerdos internacionales.

a) A este respecto, en el artículo 9, bajo el rótulo «Derecho a contraer matrimonio y derecho a fundar una familia", solamente se en-

${ }^{23}$ Cfr. Stern, K./Tettinger, P. J., en: Stern/Tettinger (Coords.), Kölner Gemeinschaftskommentar zur Europäischen Grundrechte-Charta, 2005, C.H. Beck Verlag, Comentario al Preámbulo. 
cuentra la fórmula: "Se garantiza el derecho a contraer matrimonio y el derecho a fundar una familia según las leyes nacionales que regulen su ejercicio" ${ }^{24}$.

En un verdadero alarde de fórmula de compromiso esta remisión supone, de manera en mi opinión lamentable, la entrega del matrimonio y la familia a la discreción legislativa de los Estados miembros ${ }^{25}$. Ciertamente nos encontramos con que la Unión Europea carece de potestad alguna de definición sobre estos conceptos; pero tampoco goza de apoderamiento alguno para disolver estos conceptos. El artículo 9, sin embargo, no se refiere para nada a una unión de hombre y mujer, a diferencia del artículo 12 del Convenio Europeo de Derechos Humanos, que encuentra ahí su fundamentación. El matrimonio es, sin embargo, un valor constitucional clásico de Europa, el cual no sólo se manifiesta en su elemento de convivencia, sino también y al mismo tiempo se aprecia como presupuesto tipológico de unas bases fiables para la educación conjunta de los hijos, como en el caso del Derecho alemán se deduce de la consideración conjunta de los arts. 6.1, 6.2 y 6.5 de la GG ${ }^{26}$.

b) Como un elemento que contribuye a mermar todavía más la protección del matrimonio y la familia en este sentido, percibimos una evidente voluntad reguladora del creador de la Carta en el art. 21.1 - como también se establece ya en el art. 13 TCE- que prohíbe la discriminación en términos generales por razón de la orientación se$x{ }^{27}$. Aquí se incluye asimismo la ya clásica y fundada comprensión, fijada por parte de la dogmática jurídica alemana, de la prohibición de la discriminación, como un concepto que en la práctica sólo puede eliminar aquellas actuaciones que conllevan un trato desigual, sin que

${ }^{24}$ La aclaración de la Comisión redactora afirma: «Este artículo se apoya en el artículo 12 del Convenio Europeo de Derechos Humanos, que dice: los hombres y las mujeres aptos para el matrimonio tienen el derecho, conforme a las leyes estatales que regulan su ejercicio, a contraer matrimonio y a formar una familia'. A la vista de la evolución social se modificó la formulación del artículo, para abarcar casos en los que las disposiciones jurídicas de Estados singulares reconocen otras formas distintas del matrimonio para formar una familia. Mediante estos artículos ni se prohíbe ni se prescribe el otorgamiento del estatus matrimonial a las uniones de personas del mismo sexo", CHARTE 4471/00, p. 11.

${ }^{25}$ Cfr. Tettinger, P. J (Nota a pie de página núm. 2), p. 1010 y ss., en especial p. 1012.

${ }^{26}$ En este sentido, vid. de modo especial TetTINGER, P. J, «Der besondere Schutz von Ehe und Familia», en: Essener Gespräche, Tomo 35, 2001, pp. 131 y ss.

${ }^{27}$ Cfr. al respecto TJCE, caso "Grant/South-West Trains», en EuZW 1998, pp. 212 y ss.; en especial p. 215, Número marginal 47 y ss. 
exista una sólida base jurídica ${ }^{28}$, en un sentido que se extiende claramente a la defensa general frente a cualquier perjuicio y con ello se abarca también las correspondientes políticas de reforma.

De igual modo, en la Directiva del Consejo relativa al establecimiento de un marco general para la igualdad de trato en el empleo y la ocupación se afirma, en su art. 2.2: "existirá discriminación directa cuando una persona sea, haya sido o pudiera ser tratada de manera menos favorable que otra en situación análoga por alguno de los motivos mencionados en el artículo $1 »^{29}$.

El artículo 21.1 podría abrir el camino al «matrimonio de homosexuales" y tener una equivocada virtualidad simbólica, sobre todo a la vista del desarrollo demográfico de algunos de sus Estados miembros. Resulta más bien dudoso que el art. 52, en su párrafo $3^{30}$, pueda actuar como "freno de emergencia", ya que es de esperar, como ya se ha dicho, que el Derecho de la Unión garantice una protección más amplia, en este ámbito, a través de una compensación "progresiva". El valor objetivo contenido en la institución matrimonial se queda olvidado por el camino. Así, la última frase del texto explicativo presenta un débil consuelo a esta situación. En este punto es necesario emprender alguna acción enérgica en contra de esta tendencia, si no se quiere convertir en real la provocante pregunta de una monografía inglesa aparecida hace pocos años («The End of Marriage?») 31 . Al menos la doctrina jurídica - que por cierto es curiosamente muy escasa - parte de la base de que las garantías correspondientes a este ámbito deben contribuir a mantener el statu quo antes que animar a "cambios progresivos» ${ }^{32}$. El

28 Véase también TEDH, caso "Tiemann/Alemania», en NJWE-FER 2001, pp. 202 y ss., en especial p. 20).

29 Directiva 2000/78/EG del Consejo de 27.11.2000 sobre la fijación de un marco general para la realización de un tratamiento igualitario en el empleo y el trabajo (Abl. L 303/16).

${ }^{30}$ Este artículo dice: "Soweit diese Charta Rechte enthält, die den durch die Europäische Konvention zum Schutze der Menschenrechte und Grundfreiheiten garantierten Rechten entsprechen, haben sie die gleiche Bedeutung und Tragweite, wie sie ihnen in der genannten Konvention verliehen wird. Diese Bestimmung steht dem nicht entgegen, dass das Recht der Union einen weiter gehenden Schutz gewährt."

31 Cfr. LEWIS, J., "The End of Marriage?, Individualism and Intimate Relations», 2002.

32 Véase McGLYNN, C., "Families and the European Union Charter of Fundamental Rights: progressive change or entrenching the status quo?», E.L.Review 26 (2001), pp. 582 y ss. 
desarrollo de la política de derechos en España parece contradecir sin embargo esta tesis.

Un derecho especialmente interesante en el contexto del matrimonio y la familia lo encontramos en el art. 24 de la Carta Europea. En él se formulan los derechos de los niños. Su párrafo 1 dice textualmente: "Los menores tienen derecho a la protección y a los cuidados necesarios para su bienestar. Podrán expresar su opinión libremente. Esta será tenida en cuenta en relación con los asuntos que les afecten, en función de su edad y de su madurez».

Con buen criterio, el párrafo 2 considera el bienestar del menor como una "cuestión primordial», en todos aquellos actos relativos al menor llevados a cabo por autoridades públicas o instituciones privadas. También hay que alabar lo estipulado en su párrafo 3, según el cual todo menor tiene derecho a mantener de forma periódica relaciones personales y contactos directos con su padre y con su madre, salvo que sean contrarios a sus intereses. Esta norma recoge un principio fundamental de las relaciones paterno-filiales, también presente en el párrafo 2 del art. 6 de la Ley Fundamental alemana. Teniendo en cuenta la teoría general de los Derechos Fundamentales hay que señalar que, en el art. 24.2, se detecta a primera vista un efecto horizontal; pero ¿no debería reflejarse este efecto también en la institución del matrimonio y en las demás relaciones filiales?

Titulares del derecho son niños, en otras palabras básicamente personas que no han llegado todavía a cumplir los dieciocho años de edad. Afectados están también según esta versión del texto los ciudadanos, en la medida en que no se descarta una eficacia horizontal o frente a terceros (Drittwirkung) ${ }^{33}$. El origen de esta regulación es la Convención de Nueva York sobre los Derechos del Niño de 20.11.1989, ratificada por todos los Estados miembros ${ }^{34}$. No entra aquí sin embargo en cuestión el derecho de los padres a "garantizar la educación y la enseñanza de sus hijos conforme a sus convicciones religiosas, filosóficas y pedagógicas" (Art. 14.3 de la Carta Europea de Derechos Fundamentales).

Un importante paso más también en este contexto es, finalmente, el artículo 33 de la Carta Europea de Derechos Fundamentales, que tiene su origen en el art. 16 de la Carta Social Europea. El art. 33.1 de la

${ }^{33}$ Cfr. Streinz, R., en Streinz (Coord.), EUV/EGV, 2004, Art. 24 de la Carta de Derechos de la UE, Número marginal 4.

34 Véase para Alemania la Ley de 17.2.1992 (BGBI. II S. 121). 
Carta dice: "Se garantiza la protección de la familia en los planos jurídico, económico y social». El apartado 2 de dicho precepto garantiza un permiso pagado por maternidad y a un permiso parental con motivo del nacimiento o de la adopción de un niño. No obstante, el ámbito de aplicación del artículo 33 de la Carta está limitado por lo dispuesto en los arts. 51.2 y 52 del mismo texto normativo ${ }^{35}$.

A pesar de todo, no deben ser subestimadas las ideas contenidas en dicho precepto, que forma parte del cuarto Capítulo de la Carta, que lleva la rúbrica "Solidaridad", y con ello pone de relieve una especial posición valorativa de la institución familiar en el contexto de los principios sociales fundamentales. Es más loable esta regulación que la de otras posiciones relativas a ciertas orientaciones y valores - podemos reseñar de nuevo la escasa reflexión sobre las raíces cristianas o la ya citada fórmula de compromiso relativa al matrimonio- que se revelan como demasiado pobres. Además hay que esperar a ver si la jurisprudencia del TEDH relativizadora del valor de la familia puede afectar también negativamente a la Carta Europea de Derechos Fundamentales.

\section{LA NUEVA JURISPRUDENCIA DEL TEDH Y DEL TJCE}

Frente a estas opiniones orientadas a la defensa de unos valores, hace ya 18 años que nos encontramos no solamente con la actual jurisprudencia del Tribunal Constitucional federal alemán, sino que, en todo este tiempo, el TEDH y el TJCE ofrecen también, por desgracia, un programa claramente diferente.

Esto debe ser analizado a través de cinco ámbitos temáticos, en concreto el status jurídico-personal de los transexuales, el concepto de familia del TEDH; el significado de matrimonio y familia como obstáculo para las limitaciones de los derechos de los extranjeros, en este caso, entre otras cuestiones, pueden citarse el derecho a la entrada y a la permanencia en el país, y especialmente lo que se refiere a la poligamia; el interés del niño en lo que se refiere al derecho de custodia así como, finalmente, el llamado "nacimiento anónimo".

Recientemente se ha resaltado de nuevo y de modo muy claro, por parte de la Sala Segunda del Tribunal Constitucional alemán, en Sen-

35 Cfr. Streinz, R., (Nota a pie de página núm. 33), Art. 33, Número marginal 3; Tettinger, P. J., en: Stern/Tettinger (Coords.), Kölner Gemeinschaftskommentar zur Europäischen Grundrechte-Charta, 2005, Art. 33. 
tencia de 11.3.2004, que debe tenerse en cuenta la situación actual de desarrollo del CEDH para la interpretación de la Ley Fundamental alemana $^{36}$. La jurisprudencia del TEDH es asumida por lo tanto como ayuda interpretativa para la reflexión sobre el contenido y alcance de los derechos Fundamentales. Para el caso en cuestión, sobre la expulsión de un extranjero de segunda generación (hijos de los extranjeros llegados a Alemania unos años antes), esto significa que en el análisis de la proporcionalidad previsto en la Constitución deben incluirse también los criterios de ponderación tenidos en cuenta por el TEDH y se requiere además un análisis comparativo con los resultados de la ponderación alcanzados por el TEDH ${ }^{37}$.

Sobre la base de un esmerado análisis jurisprudencial, el Tribunal alemán acabó estableciendo "que también teniendo en cuenta la jurisprudencia del TEDH, la expulsión del recurrente no resulta desproporcionada, a la vista de los arts. 6.1, 2.1 y $1.1 \mathrm{GG}$, considerando que el recurrente no está casado, no tiene niños, es un extranjero de segunda generación, que ha sido varias veces condenado con penas privativas de libertad o penas aplicadas a menores de edad, y que entiende al menos en lo fundamental la lengua propia del Estado del que posee la nacionalidad ${ }^{38}$.

Asimismo, otras sentencias espectaculares de tiempos más recientes como "Carolina de Mónaco» ${ }^{39}$ o también "Görgülü» ${ }^{40}$ ponen de relieve que la jurisprudencia del Tribunal de Estrasburgo puede todavía revelar nuevos puntos débiles en un sistema jurídico como el alemán que creíamos casi completo ${ }^{41}$.

\section{EL CONCEPTO DE FAMILIA DEL CONVENIO EUROPEO DE DERECHOS HUMANOS}

EI TEDH interpreta el concepto de familia de un modo extremadamente amplio. Desde su punto de vista, el concepto se ha desarrollado más allá de lo que representa el clásico modelo de familia y apenas se

36 BVerfG, EuGRZ 2004, 317 (318 y ss.).

37 BVerfG, EuGRZ 2004, 317 (319).

38 BVerfG, EuGRZ 2004, 317 (321).

39 TEDH ("Carolina/Alemania»), NJW 2004, p. 2647.

40 TEDH ("Görgülü/Alemania»), NJW 2004, p. 3397.

41 Cfr. también Tettinger, P. J. (Nota a pie de página núm. 1), p. 1144; además BRÜCKNER, Ch., "Väterrechte vor dem Europäischen Gerichtshof für Menschenrechte", FPR 2005, pp. 200 y ss. 
pone ya más en estrecha correlación con la institución del matrimonio. Una clara muestra del carácter de sus ideas actuales lo ofrece el Tribunal en una decisión de la Gran Sala de 13.7.200042.

Se trata en este caso de un padre que reclamaba el derecho al trato regular con un hijo fruto de una relación no matrimonial, después de haberse separado de su compañera y madre de su hijo, trato que en un principio él había tenido. Los tribunales alemanes habían rechazado las correspondientes solicitudes, de modo parcial y sin comparecencia oral, con el fundamento de que no procedía la imposición de un acceso al trato con el niño debido a las tensas relaciones del padre con la madre; esto sería de tal modo evidente, que no haría necesario siquiera la petición de un informe psicológico pericial. EI TEDH apreció aquí una violación del art. $8 \mathrm{CEDH}$. En su sentencia señaló el Tribunal que no consideraba el concepto de familia al que se hace alusión en art. 8 CEDH limitado sólo al tipo de relaciones basadas en el matrimonio, sino que podía ampliarse también a otras relaciones familiares de facto, cuando los afectados conviven sin que exista matrimonio ${ }^{43}$. Un niño nacido en el contexto de unas relaciones de este tipo estaría, desde el momento de su nacimiento y por la sola circunstancia de su nacimiento, formando parte de esa "unión familiar». En este caso concreto se había puesto de manifiesto que el recurrente no había podido participar en el proceso con las suficientes garantías, puesto que no se llevó a cabo una comparecencia oral ni se requirió ningún informe independiente. Todo ello conducía, como resultado final, a una violación del art. 6.1 del CEDH.

Precisamente la jurisprudencia se ha vuelto a ocupar, en tiempos recientes, del derecho del niño al acceso a sus dos progenitores, incluso al padre que no tiene derecho de custodia, como por ejemplo en el caso Görgülü contra Alemania44. De lo afirmado en esta Sentencia se deduce que no puede desarrollarse un lazo natural entre padre e hijo, si no se le permite al padre biológico reunirse con su hijo. Mantener ín-

42 Cfr. TEDH («Elsholz/Alemania»), NJW 2001, p. 2315; sobre esto BENDA, E., "Verkehrtes zum Verkehrsrecht», EuGRZ 2002, pp. 1 y ss.

${ }^{43}$ Cfr. también TEDH («Petersen/Alemania»), NJW 2003, p. 1921; crítico sobre esta jurisprudencia sobre esta jurisprudencia del derecho a relacionarse con el menor (Verkehrsrecht) del padre no matrimonial se muestra E. Benda (Nota a pie de página núm. 42), p. 3, que habla de un "sentimiento de veleidad» («Gefühl der Unberechenbarkeit»).

${ }^{44}$ Cfr. TEDH ("Görgüglü/Alemania»), NJW 2004, p. 3397; sobre ello vid. LENZ, Ch./ BAUMANN, J., "Umgangrecht auf internationaler Ebene, insbesondere vor dem EGMR», FPR 2004, p. 303; además BVerfG, EuGRZ 2004, pp. 741 y 809. 
tegros los vínculos familiares es algo que sirve al interés superior del menor; separar a un menor de sus raíces sólo podría justificarse en circunstancias extraordinarias. En el caso Haase contra Alemania, el TEDH puso de relieve que también la obligación de atender a la vida familiar puede hacer surgir la obligación de garantizarla ${ }^{45}$. Por principio, el Estado debería comportarse de tal manera que permitiese el desarrollo de los vínculos familiares, y debería tomar las medidas necesarias que hiciesen posible la vida en común de padres e hijos.

\section{CONCLUSIONES}

Finalmente, nos queda todavía algo de tiempo para hacer un breve resumen de lo expuesto. He procurado dar un pequeño vistazo a algunos aspectos que afectan especialmente a la perspectiva alemana, española y europea. Por ello he tenido que dejar al margen algunos problemas conocidos, como la gran cuestión de los derechos de los transexuales, el nacimiento anónimo, el matrimonio homosexual o las parejas de hecho registradas legalmente, que se han previsto jurídicamente en Alemania.

No se ha propuesto correctamente en Europa hasta ahora un camino para la protección coherente del matrimonio y la familia.

Las garantías de protección que figuran en el Derecho de los tratados internacionales -que por su parte son difícilmente ejecutables de modo directo- son en muchos casos más precisas y expresivas que las establecidas en la Carta Europea de derechos y el CEDH —en todo caso, al menos, en el sentido en que éstas son interpretadas por la más reciente jurisprudencia del TEDH y el TJCE-.

La excepción del reconocimiento de los derechos especiales de los niños en la Carta Europea de Derechos podría significar sin embargo un cambio tendencial, e incluso, como consecuencia, una mayor acentuación de los derechos comunes de los padres y del creciente planteamiento de algunos problemas típicos con relación al superior interés del menor, que afectan al matrimonio y la familia.

A largo plazo se necesita una estrategia amplia y acertada, para asegurar la correspondiente prioridad y coherencia a esos dos modelos fundamentales, como por ejemplo se ha hecho por parte de los Confe-

45 Cfr. TEDH («Haase/Alemania»), NJW 2004, p. 3401 y ss., especialmente p. 3404, número marginal 84 y ss. 
rencia de Obispos Europeos ${ }^{46}$ en el marco de una «Estrategia para la familia en la Unión Europea», tomando en consideración los siguientes puntos programáticos:

- Mejorar la integración de las personas mayores en la sociedad, sobre todo en todo lo que pueda ayudar a sus familias a prestarles la asistencia necesaria;

- Promover disposiciones y políticas más justas y favorecedoras de los intereses del menor;

- Fomentar normas y políticas más justas con relación a las exigencias planteadas por el matrimonio y la paternidad;

- Promover la estrecha relación entre generaciones;

- Mejorar la protección de la familia en especiales situaciones de necesidad;

- Promover una mejor representación de la familia en la vida pública.

En definitiva, debería evitarse la práctica de un tipo de política en el que primase una suerte de competición por servir a los demás a través de la toma de decisiones populares, sin ofrecer soluciones a los problemas realmente importantes.

\section{Resumen}

El matrimonio y la familia se encuentran bajo la particular protección del sistema estatal del artículo 6.1 de la Constitución alemana. EI artículo analiza hasta qué punto esto es cierto tanto en el ordenamiento jurídico alemán como en el europeo. El punto de partida es el hecho de que, a pesar de que el matrimonio y la familia sean objetos independientes de protección jurídica, ambos están inseparablemente unidos. Son de modo natural dos presupuestos esenciales para la pervivencia de la humanidad y de sus naciones. Además, se ha de tener en cuenta que en toda Europa, sobre todo en países como Alemania, Italia y España, se registran en la actualidad dramáticos cambios demográficos, se reduce el número de nacimientos y se eleva la media de edad.

El matrimonio, la familia y el derecho a la educación son objeto de preocupación internacional así como de las Declaraciones de protección

${ }^{46}$ COMECE (Coord.), Eine Familienstrategie für die Europäische Union, Marzo 2004 , pp. 7 y ss. 
de Derechos Humanos. Asimismo, el tradicional instituto jurídico de la pareja monógama como la unión en absoluta igualdad de condiciones del hombre y la mujer pertenece a los valores culturales centrales europeos, y así se recoge en sus constituciones, en los arts. 8 y 12 del CEDH y en la propia Carta de Derechos Fundamentales de la UE. Aunque no tenga todavía fuerza legal, se tiene en cuenta por parte de la interpretación jurisprudencial. El artículo 9 de dicha Carta, sin embargo, no se refiere para nada a una unión de hombre y mujer, a diferencia del artículo 12 del Convenio Europeo de Derechos Humanos, que encuentra ahí su fundamentación, y deja al arbitrio de cada Estado la definición del matrimonio.

La jurisprudencia de los Tribunales de Luxemburgo y de Estrasburgo ha confirmado un cambio en cinco ámbitos temáticos: el status jurídico-personal de los transexuales, el concepto de familia del TEDH; el significado de matrimonio y familia como obstáculo para las limitaciones de los derechos de los extranjeros, en este caso, entre otras cuestiones, pueden citarse el derecho a la entrada y a la permanencia en el país, y especialmente lo que se refiere a la poligamia; el interés del niño en lo que se refiere al derecho de custodia así como, finalmente, el llamado "nacimiento anónimo".

Las garantías de protección que figuran en el Derecho de los tratados internacionales - que por su parte son difícilmente ejecutables de modo directo- son en muchos casos más precisas y expresivas que las establecidas en la Carta Europea de derechos y el CEDH —en todo caso, al menos, en el sentido en que éstas son interpretadas por la más reciente jurisprudencia del TEDH y el TJCE-. En consecuencia, es necesario emprender todavía en Europa un camino para la protección coherente del matrimonio y la familia.

\title{
Palabras clave
}

Derecho europeo, protección del matrimonio y la familia.

\begin{abstract}
Under paragraph 6, subsection 1 of the German Constitution, marriage and family are under the particular protection of the state system. The article analyses whether this is true within the German and European legal system. Starting point is the fact that although marriage and family are independent objects of legal protection, they are however inseparably linked. They are by nature essential for the preservation of humankind and its nations. In addition to changed
\end{abstract}


interpretations of objects of legal protection by the highest European courts, there are currently dramatic changes developing that reveal a strong decline in the rate of births and an increasing ageing of society.

Marriage and family are the subjects of international agreements as well as of declarations regarding the protection of human rights. Equally the member states of the European Union have standardised the protection of marriage and family in their constitutions, even if they differ in legal form and levels of protection. Paragraphs 8 and 12 of the ECHR join the regulations of the Charter of Fundamental Rights of the European Union (para. 7, 9 and 33 of the Charter of Fundamental Rights). The Charter of Fundamental Rights may not yet have legal force, but it is already increasingly used as a source of information for literature and practice. Para. 9 of the Charter of Fundamental Rights remains however an anaemic formula since marriage and family are given over to the legislative arbitrariness of the member states. The European Court of Justice in Luxembourg and the European Court of Human Rights in Strasbourg have almost completely renounced their formerly value-oriented decisions with their decisions on the status of transsexuals, on anonymous births or on gay marriages. Thus the term 'family' is now interpreted within a framework that extends far beyond the classical image of family and is hardly used anymore in close correlation to the institution of marriage. Therefore things for the coherent protection of marriage and family in Europe are far from going well. The hardly enforceable safeguards of the international contract law are frequently more concise and significant than the standards of the Charter of Fundamental Rights and the European Convention on Human Rights, at least based on the decisions of the courts of justice in recent years and their interpretations. In the long term therefore a comprehensive strategy is needed in order to ensure the priority and coherence for the fundamental guiding principles of marriage and family that they are due.

\section{Key words}

European Law, Protection of Marriage and family. 